\title{
Slope Stability Considerations in Integrated Surface Mine Design
}

\author{
M. Grenon Université Laval, Canada \\ J. Hadjigeorgiou Université Laval, Canada \\ P. Côté Université Laval, Canada
}

\begin{abstract}
This paper provides the framework for integrating slope stability considerations in the early stages of mine planning for surface mine operations. The block model and the resulting pit optimisation shells are linked to a series of algorithms that are used to identify potential instability areas in any particular pit of the mining push-backs. The algorithms have been developed to facilitate limit equilibrium stability analyses and to construct and visualise 3-D susceptibility maps. This has resulted in an integrated process that allows for continuous updating of the stability and mine models from feasibility to production.
\end{abstract}

\section{Introduction}

Computerised surface mine planning and design has reached a relatively mature stage. In a feasibility study once block modelling of ore grades and pit optimization is completed, the input of geotechnical specialists is required to investigate the stability of a series of slope configurations. This is often an iterative process whereby different scenarios are investigated until an economic and geotechnical acceptable slope design is reached. This approach does not facilitate an integrated data management technique and the iterative process can be long, particularly if the mine optimisation and geotechnical analysis are outsourced. Furthermore, managing of economic and geomechanical data is often compartmentalised which makes revision of mine plans somewhat awkward and time consuming.

This paper presents an integrated methodology where there is common management of economic, geological, mining and geomechanical data. The advantages of linking geotechnical databases to mine planning software have been demonstrated by Little (2006). Responding to a need to manage vast amounts of geotechnical data at the Potgietersrust Platinums Ltd (PPRust) open pit operations of Anglo Platimum a series of geotechnical databases were developed to record logging, mapping and rock testing data. These were complemented by slope monitoring, rainfall and groundwater databases. In order to ensure that the more up to date geotechnical data are used for planning purposes the databases were linked to the mine drafting (AutoCAD ${ }^{\mathrm{TM}}$ ) and modelling (Datamine ${ }^{\mathrm{TM}}$ ) packages.

The innovation of the present work lies in linking slope stability assessment algorithms into a commercially available mine design software (Surpac Vision ${ }^{\mathrm{TM}}$ ). This approach makes optimum use of topographical and geotechnical data integrated into the mine design software database. A Geographical Information System (GIS) is subsequently used to establish the slope orientations of the designed optimised pits and develop a slope stability hazard assessment system. This is done on a cell by cell basis and results in the automatic generation of a 3-D pit map identifying cells of potential slope instability. This information is used to illustrate areas of potential slope instability which are superimposed on the pit geometry. As more geotechnical data become available, it is then a routine process to update stability hazard maps for the design open pit. The developed methodology is illustrated by means of a worked example where it has been successfully integrated in a mine planning software and is used to explore different mining scenarios.

\section{Resource modelling}

One of the first steps in the mine life-cycle is to define the orebody limits and resources. The success of any resource estimation is highly dependent on the quality of collected and assayed samples usually obtained through diamond drilling. Geostatistical techniques are employed to establish the spatial variability of the geological resources and block modelling is used to represent the spatial distribution of ore grades. Block 
modelling is simply a subdivision of space into smaller blocks with the size of selected blocks usually dictated by the diamond drilling pattern and the mining bench height. Ore grades are interpolated within those blocks based on simple or advanced, geostatistical methods (e.g. inverse distance, ordinary kriging and indicator kriging). Once the block model is obtained optimal pit limits are identified. Pit optimization is a critical function when it comes to examining the economics of an open pit mine, at both the feasibility and production stages. Pit optimisation is usually based on the Lerchs-Grossman algorithm (1965) and can account for the influence of slope configuration, operating costs, product prices etc. This is subsequently subject to geotechnical review to establish the stability of the design slopes.

Block modelling functions available within commercially available resource and mine planning numerical tools are used almost exclusively to evaluate geological resources and mining reserves. One way to maximize their use, and hence optimise the pit design process, would be to fully integrate block modelling tools and slope stability analysis. Most mines already assign the rock type to every block. This process can be further enhanced by introducing a rock quality value to every block. This could be a simple index such as $\mathrm{RQD}$ or a rock mass classification value. Practically all commercial packages can also store information on major structural features such as faults, dykes or geological contacts. An integrated process will take into consideration this information to facilitate slope stability investigations.

\section{Preliminary evaluation of slope stability}

A conventional requirement during feasibility studies is to determine if the optimised pit slopes are safe. This information is used to determine ore to waste ratios and preliminary pit layouts. Preliminary slope stability analysis at the early stages often relies on limited geotechnical data. An important consideration is the identification of areas in a mine that are more susceptible to slope failure assuming a particular failure mode. The open pit example reported by Hoek and Bray (1981) and reproduced by Wyllie and Mah (2004) illustrates a useful visualisation of the results of a slope stability analysis for a proposed open pit mine, Figure 1.

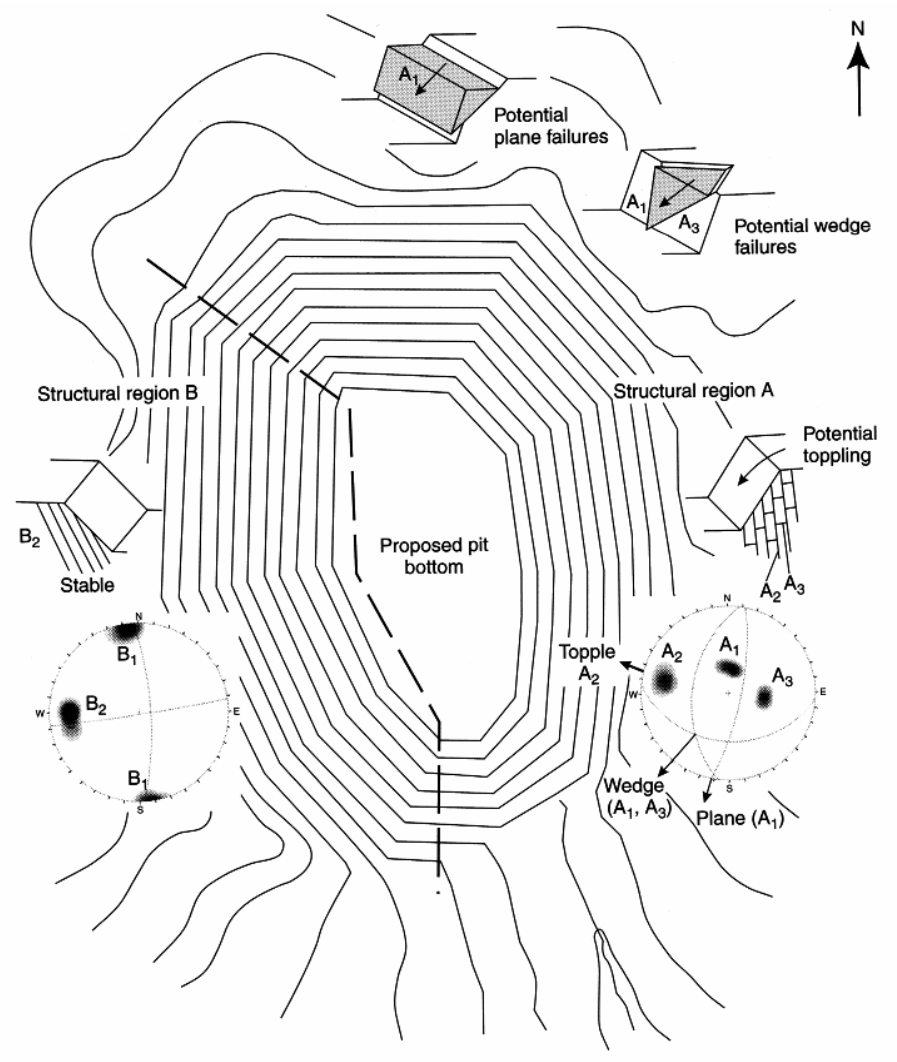

Figure 1 Preliminary evaluation of slope stability of proposed open pit mine, after Hoek and Bray (1981) reproduced from Wyllie and Mah (2004) 
The main limitations of this approach are the quality and quantity of field data. If adequate data are available it is then possible to identify different zones of similar rock mass quality and structure. The potential failure mechanisms are investigated for representative slopes and the stability of selected cross sections is determined using limit equilibrium models. This process can be time consuming particularly if the pit geometry is complex and in the presence of different ground conditions.

Once the slope stability investigations are completed and the results and the design slopes are accepted by mine management, a good part of the geotechnical work is concluded. In most cases the geotechnical analysis is conducted independent of the resource modelling. Quite often the geotechnical and/or the resource modelling are outsourced. This can result in further delays until an acceptable design is achieved.

\section{Data management}

Integrated surface mine design implies the use of all pertinent information and the linking of economic, operational and slope stability issues. This necessitates that data are easily transferred and accessed by the different mine planning and design modules and that a platform is available to manage and visualise this information. In this context the use of geographical information systems (GIS) provides a framework to manipulate electronic representations of geographic data by facilitating the creation, use, and presentation of geographic data in a preferred format depending on the objectives.

In GIS, map data is any variable or set of variables representing a set of geographic locations, properties of a region, or features on a planet's surface, regardless of how large or complex the data is, or how it is formatted. Such data can be rendered as maps in a variety of ways using the provided functions and user interfaces. Slope stability applications, in GIS environment make use of raster geodata. In this context, raster data are the results of a systematic scan of an image that encodes it into a regular grid of pixel values arrayed in rows and columns. When data in raster format represent surface ground conditions they are referred to as a data grid, and the data is stored as an array or matrix. Raster geodata differ from other matrix representations by the fact that they are referenced with respect to the globe or any particular map projection. In reality they employ a terrestrial coordinate system that can be shared by other geospatial data.

There are several GIS systems that can be used in slope stability applications. For the purposes of this paper it was expedient to use the Mapping Toolbox in MATLAB ${ }^{\mathrm{TM}}$. Map data were represented as a matrix (a 2-D $M_{A T L A B}{ }^{T M}$ array) with each row-and-column element corresponding to a rectangular patch of a specific geographic area, with implied topological connectivity to adjacent patches. A raster can encode either an average value across a cell or a value sampled at the centre of that cell. If surface elevations are part of raster geodata it is possible to construct digital elevation models (DEM), and topographical maps.

\section{$5 \quad$ Integrated design - example application}

In order to illustrate the potential for an integrated design linking block models, optimised pits and slope stability considerations, we used Surpac Vision ${ }^{\top \mathrm{M}}$, Surpac Minex Group (2006) to model a metallic ore body. The pit size was 1200 by $1000 \mathrm{~m}$ at a depth of $300 \mathrm{~m}$. The resulting ultimate pit was obtained using the Lerchs and Grossman (1965) algorithm and taking into considerations economic considerations.

\subsection{Rock mass structure and mechanical properties}

In order to illustrate the developed methodology it was assumed that the ultimate pit could be sub-divided into five distinct structural domains (401 to 405), with each domain delineated by several fracture sets. The structural domains are defined by several sets. All fracture sets are defined by their mean values and some value to define their dispersion around the mean, Figure 2. The mechanical properties of fractures are not readily available in the early feasibility stage. Usually based on core recovery the shear properties are determined. As more information becomes available the database of mechanical properties is updated.

The five structural domains were incorporated into the block model on a block by block basis using Surpac Vision $^{\text {TM }}$, Figure 3 . The selected block dimensions were 10 by 10 by $14 \mathrm{~m}$ and the mining bench was $14 \mathrm{~m}$. In Figure 3, it was also possible to locate the geological contacts between structural domains. These features were represented by three-dimensional surfaces. The same information was visualised as a 2D map using MATLAB $^{\mathrm{TM}}$ in Figure 4. 


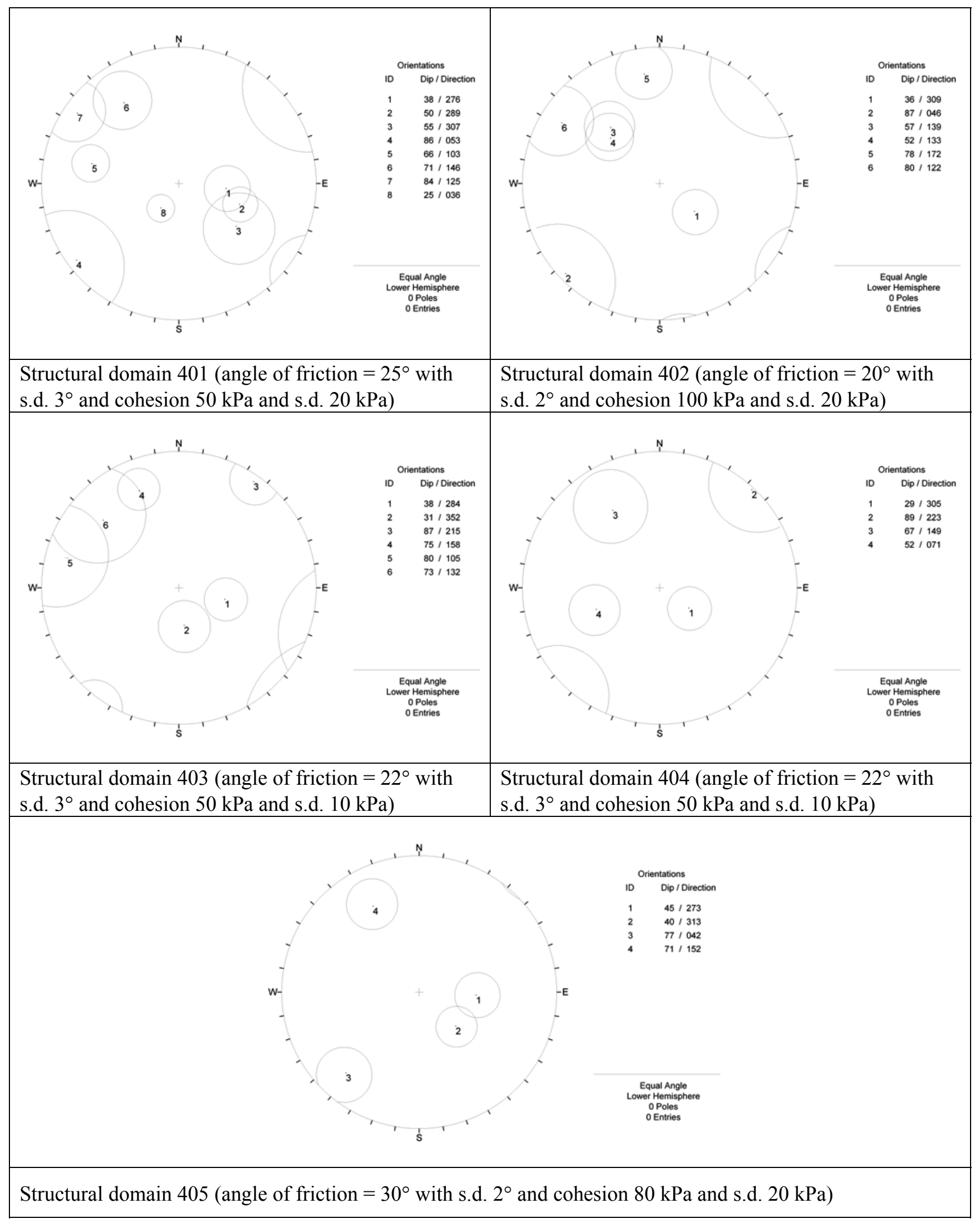

Figure 2 Stereonets for the five structural domains in the pit 


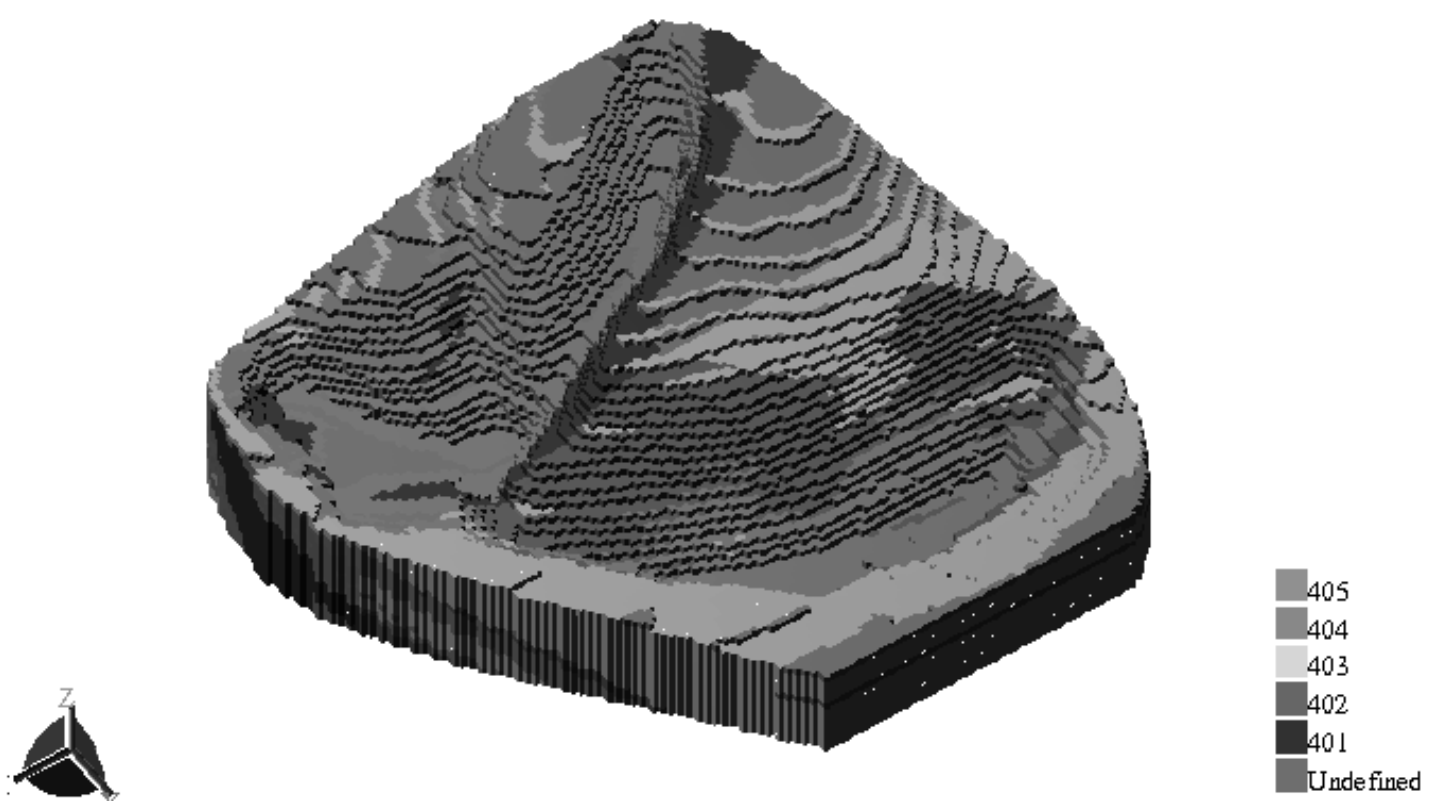

Figure 3 Ultimate pit boundaries and the representation of structural domains using block modelling

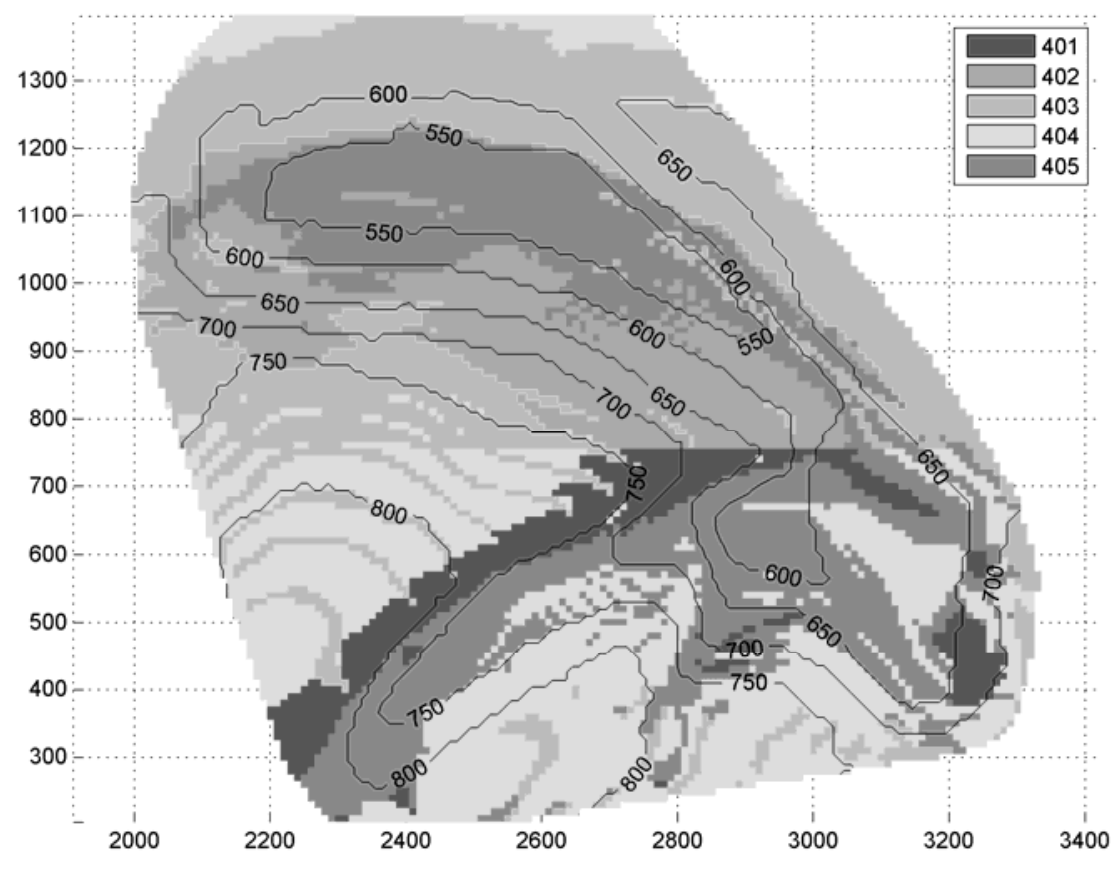

Figure 4 Ultimate pit boundaries and the representation of structural domains using MATLAB ${ }^{\mathrm{TM}}$

\subsection{Topographical information}

During feasibility and preliminary planning stages of an open pit mining project, the best possible representation of the final pit topography is obtained through block modelling. In this case study, the coordinates $(\mathrm{x}, \mathrm{y}, \mathrm{z})$, the structural and mechanical properties of the fracture sets that define the blocks located on the surface of the ultimate pit were extracted from the entire block model and exported to GIS. As in this example slope stability investigations are limited to structural failure it is the mechanical properties of the fractures and not of the intact rock that are used in subsequent analyses. 
The resulting block model for the pit was used to construct a digital elevation model. In order to undertake a comprehensive slope stability investigation, however, it is necessary to establish the orientation of all representative pit slopes. If the topographical data information is under raster format, GIS may be used to assess slope orientation on a cell by cell basis. Under the GIS environment, slope orientation is defined by slope and aspect. The slope (S) of a cell is defined by the maximal inclination of a plane formed by the centre of a cell and the centre of its immediate neighbours. The aspect (A) identifies the steepest down slope direction from each cell to its neighbours. The use of slope and aspect is equivalent to the dip and dip direction used in rock engineering to define slope orientations. Figure 5 illustrates the pit topography in 3-D projection view, while a map view is provided in Figure 6.

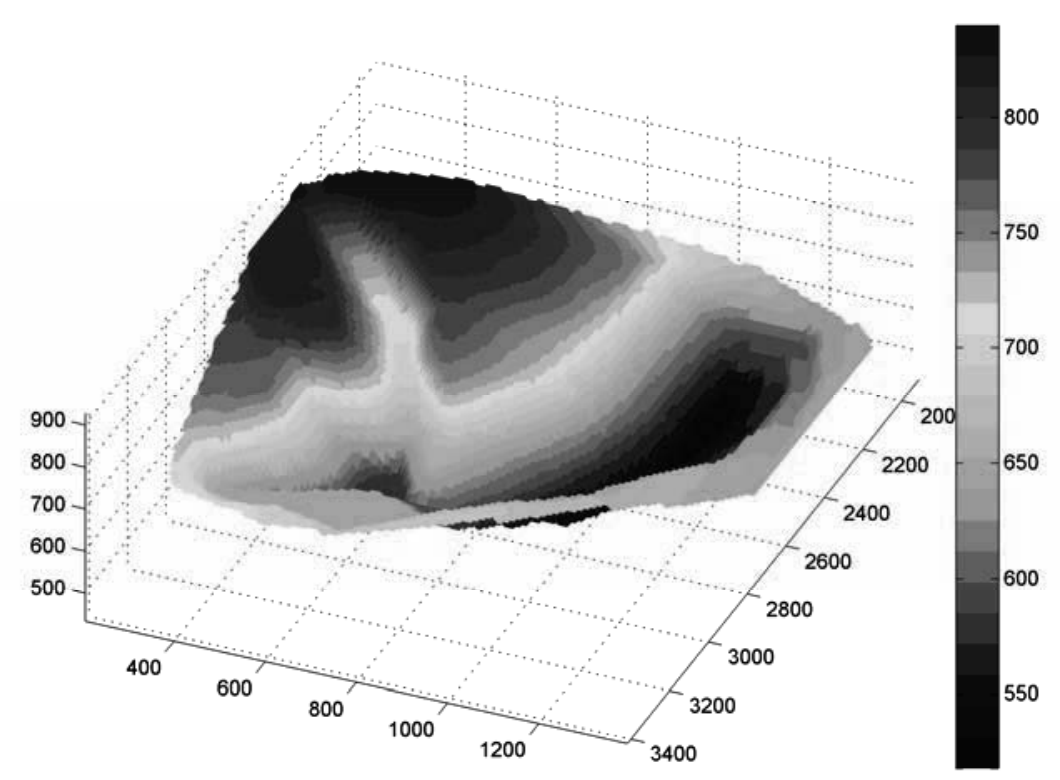

Figure $5 \quad$ Pit topography presented as a 3-D projection view

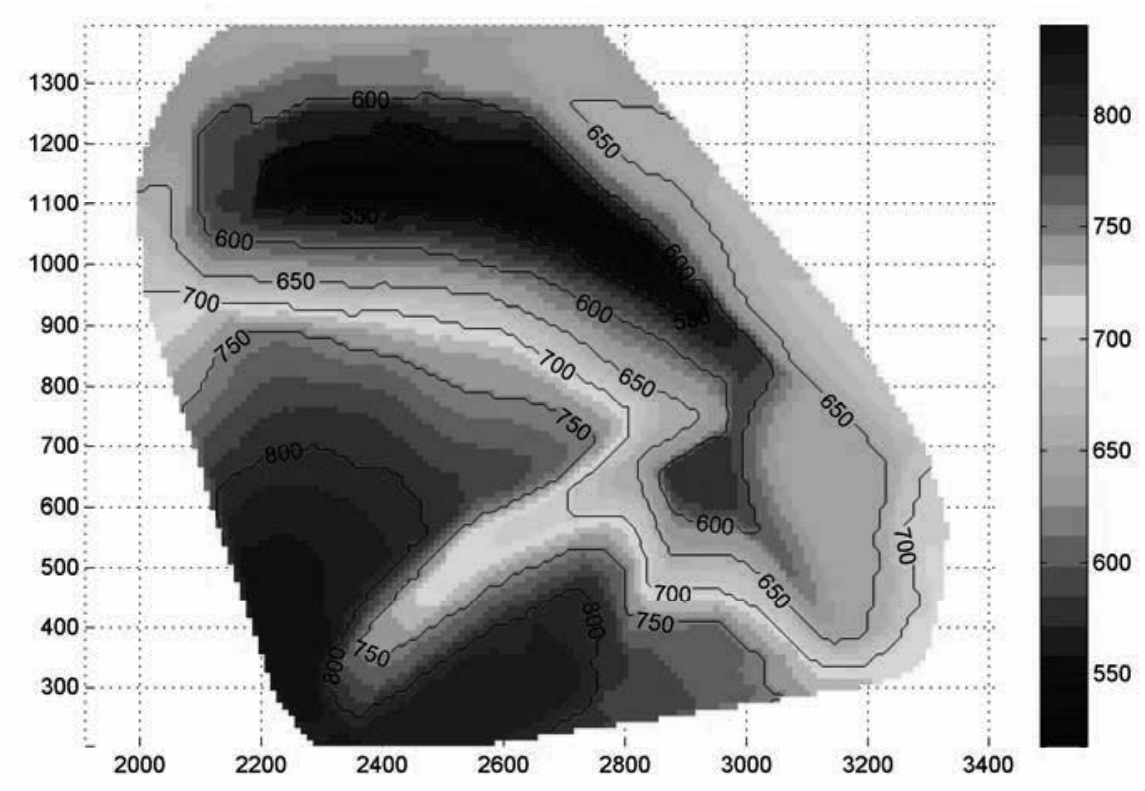

Figure 6 Pit topography presented as a 2D top view map

A topographic analysis of the whole pit requires that orientation of each cell of the DEM is known. Jaboyedoff et al. (2004), analysing natural slopes, suggested that this information can be visualised using a coloured shaded relief map combining both terrain slope angle and slope aspect. This was accomplished by 
coding the slope orientation following the hue-saturation intensity (HSI) system. This approach has the advantage that each colour is defined as a unique dip direction and dip for a slope.

A topographic analysis of the pit is presented in Figure 7. All cells are coloured based on their orientation. In this representation flat surfaces are white and steeper slopes are identified by darker colours. A stereonet is presented as a map legend. Finally, a stereonet presents a pole plot of all slopes in the pit. It should be noted that the convention used to represent slope orientation on a map is Pole Vector; the coordinates will be in trend and plunge format, and represent the pole orientation.
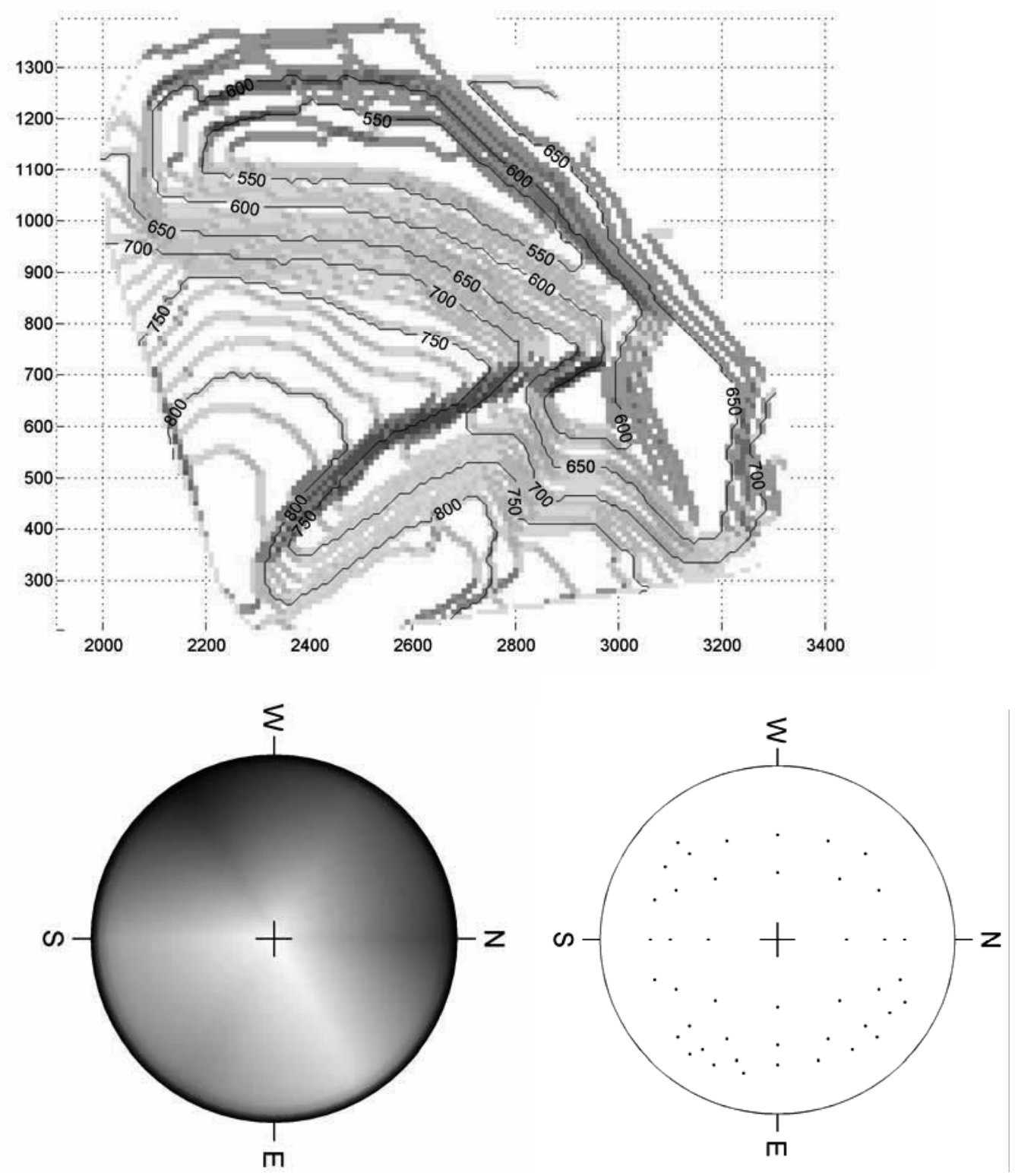

Figure 7 Map of slope orientation including 3-D colour scheme and slope orientation stereonet

\subsection{Kinematic analysis of rock slopes}

At this stage of the integrated design a 3-D pit model has been developed, the slope configurations defined and the pit has been divided into different structural regimes. The next step is to establish whether there are areas in the pit that are susceptible to structural related instability. This necessitates a preliminary investigation on possibility of failure mechanisms (planar, wedge, toppling or more complex mechanisms). A kinematic analysis investigates whether any given fracture-slope configuration is susceptible to move. In this paper only planar and wedge type failures are investigated. 


\subsubsection{Implementing kinematic failure criteria on a cell by cell basis}

At the present time the developed algorithms investigate the kinematic stability of slopes under plane and wedge failure. This was possible by implementing a vector analysis in the MATLAB ${ }^{\mathrm{TM}}$ environment, MathWorks (2006). This approach exploited the powerful computational engine for vector and matrix based calculation schemes in MATLAB $^{\text {TM }}$ and resulted in a very fast speed of execution. As the structural properties of the blocks located on the surface of the pit and their respective slope orientations were already introduced into MATLAB ${ }^{\mathrm{TM}}$, kinematic feasibility assessment for planar and wedge type instabilities was performed on every cell. Work is currently on going to integrate kinematic criteria checks to investigate the potential for toppling failures.

The conditions for kinematic feasibility are summarised in most rock mechanics textbooks, for example Hudson and Harrison (1997). For a planar instability to be kinematically feasible, there are four (4) necessary conditions:

- Dip of slope must exceed the dip of the potential slip plane.

- The potential slip plane must daylight on the slope plane.

- The dip of the potential slip plane must be such that strength of the plane is reached.

- The dip of the sliding plane should lie approximately within $\pm 20^{\circ}$ of the dip direction of the slope.

There are three necessary conditions for a kinematically feasible wedge failure:

- The dip of the slope must exceed the plunge of the intersection line of the two fracture planes associated with the potentially unstable wedge.

- The intersection line of the two fracture planes associated with the potentially unstable wedge must daylight on the slope plane.

- The dip of the intersection line of the two fracture planes associated with the potentially unstable wedge must be such that the strength of the two planes is exceeded.

The conditions for kinematic feasible planar conditions were implemented on a cell by cell basis in

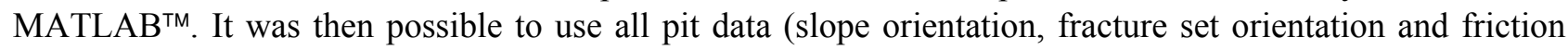
angle) to establish the kinematic feasibility of planar failure. A kinematically feasible failure was given a value of one, while a zero was assigned when kinematics indicated that failure could not occur.

Investigating whether the necessary conditions for kinematic wedge instability are met is relatively more complex under a cellular representation of space (GIS). To overcome this problem it was necessary to represent the orientation of a plane (slope face or fracture) in vector form. This was done using the direction cosine representation as explained in Priest (1993). Finally, to assess the kinematical feasibility of a wedge in a slope we employed the techniques originally outlined by Günther (2003).

Once the kinematic tests were implemented in MATLAB ${ }^{\mathrm{TM}}$ it was possible to use the structural information in the database to undertake either a deterministic or a probabilistic investigation. Deterministic investigations employ average dip, dip directions and friction angle, to determine the potential for kinematic instability. Consequently any slope area in the pit is both kinematically feasible, and assigned a value of 1 or dark grey colour, or kinematically not feasible and consequently stable and assigned a value of 0 and colour coded light grey).

In a probabilistic analysis the statistical distributions of the input parameters, in this case dip, dip direction and friction angle are used. A Monte-Carlo simulation approach is used to quantify the probability, $\mathrm{P}_{\mathrm{k}}$, for a kinematic feasible instability. $P_{k}$ is calculated for the purposes of this paper in the following way. In the first place every structural domain is already defined in the block model. For example structural domain 402, represented in Figure $2 b$ has six fracture sets. For a given cell then 10,000 fractures of every set were generated while allowing the properties to vary based on the corresponding probability distribution frequency functions. It was then possible to establish the kinematic feasibility for all scenarios. This approach provides an insight on the influence of variability within a structural domain. 


\subsubsection{Kinematic planar failure analysis}

Applying the kinematic analysis for the investigated pit it is possible to construct a map that identifies all possible locations where the slope geometry and the structural regime may result in areas of potential instability. It is noted that any particular slope is declared as potentially stable or unstable. Figure 8 illustrates the results of a kinematic analysis for potential plane failure for the designed pit. Based on the digital elevation model, slope geometry and the mean values of the structural data a series of kinematic analyses identified cells or blocks in the pit susceptible to failure. A particular cell is either susceptible to planar failure, represented in dark grey, or is deemed stable and identified by a light grey colour. In this analysis, a cell is assigned a dark grey colour even if only one fracture set is susceptible to planar failure. In this example, the slopes potentially susceptible to fail in planar mode are found mainly in the higher elevation areas.

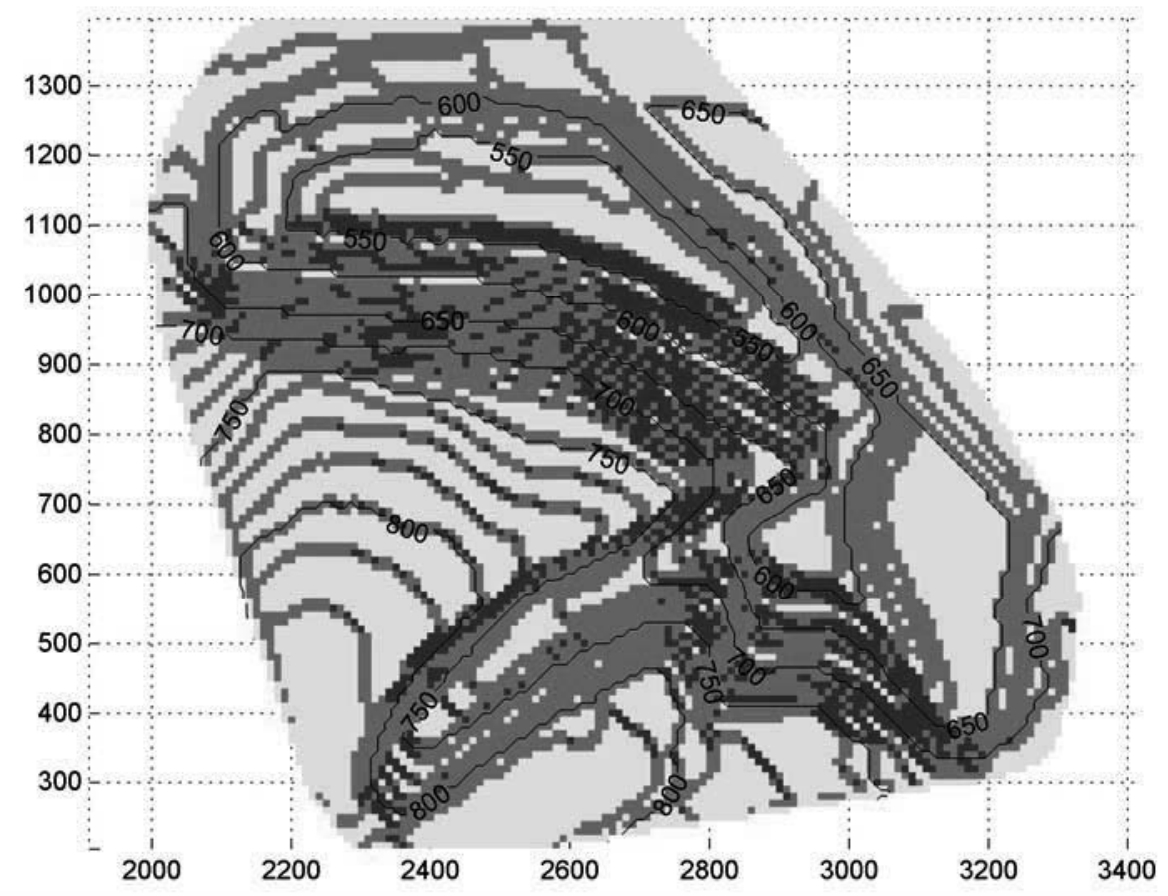

Figure 8 Map of kinematic feasible planar instability (deterministic analysis). Cells in dark grey are susceptible to failure

The use of mean values to describe the structural regime can in certain cases result in misleading interpretation of the stability concerns. All geological structural data display some inherent variability. Referring to the stereonets in Figure 2, this was quantified by the Fisher's constant for the orientation data. As the GIS module already stores this information, it is a logical step to introduce this variability in a kinematic analysis. The variability of the friction angle was also considered.

A Monte-Carlo probabilistic analysis was undertaken making use of the full structural data and variations for every structural domain. These data were stored for every cell. In the probabilistic analysis, 10,000 probable fractures are generated per set for every cell taking into consideration the statistical distribution of fracture orientation and friction cone. The developed algorithms verified if the kinematic conditions for planar failure were present for every fracture of every set of every domain. The probability of kinematic feasibility is determined on a fracture set basis.

$P_{k}=$ Number of kinematically feasible samples / Number of samples

Repeating this process, while accounting for the inherent variability of the structural data, results in a more realistic estimate of cells susceptible to failure, Figure 9. In this case it is the maximum probability of kinematic feasibility of any fracture set that is presented. Alternatively, the $\mathrm{P}_{\mathrm{k}}$ representation can be considered as the worst case scenario. It is clear that Figure 9 provides more information that can be used for decision making than Figure 8 . While Figure 8 is for practical purposes a Boolean representation (potential 
for failure or potentially stable), Figure 9 provides for a more nuanced representation of areas that should be of concern in the geotechnical design of mine slopes.

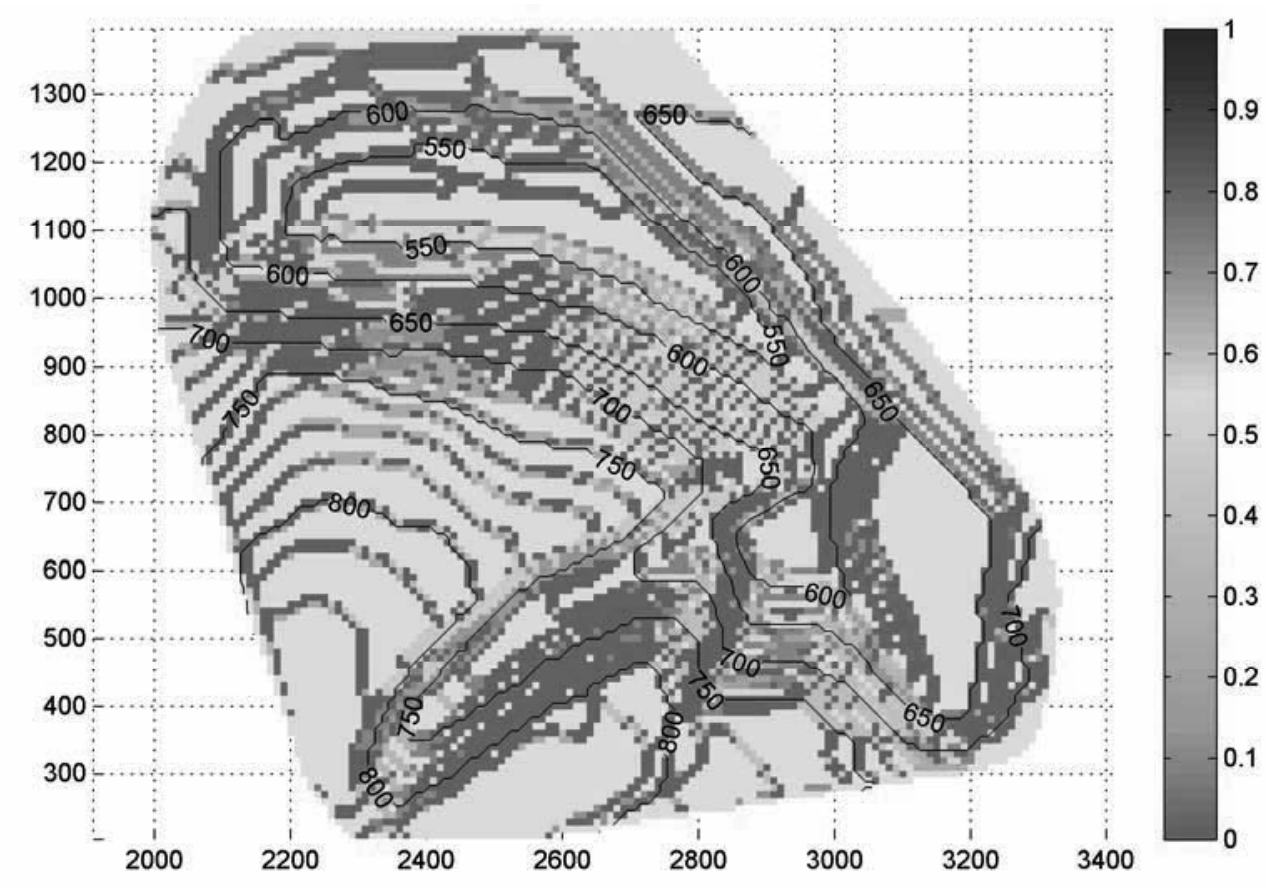

Figure 9 Map of kinematic feasible planar instability (probabilistic). Displaying the maximum probability of failure for each cell

\subsubsection{Kinematic analysis for wedge type failure}

Figure 10 illustrates the results of a kinematic analysis to identify the potential for wedge type failure. It is clear that there are zones of concern along the steeper slopes and in particular in the structural domain (403). Using the same Monte-Carlo approach as before structural variations were incorporated in the analysis. The results are illustrated in Figure 11. Comparing the results of Figure 10 and 11 it is recognised that although a similar zoning pattern is observed the probabilistic analysis suggests that the actual probabilities of failure are low. This is important information that could not have been gleaned from the Boolean approach summarised in Figure 10.

In Figure 10 many cells are problematic using the mean fracture properties values. If one however consults Figure 11, it is possible to identify regions (darker greys) that are more problematic than other given the high probability for a kinematic feasible instability of at least one of the possible fracture set combination. For planning purposes it is noted that the area to be monitored for potential instability is in domain 405 and some parts of domain 402.

\subsection{Limit equilibrium analysis of rock slopes}

Limit equilibrium analyses (LEA) are used to compute the factor of safety for a sliding surface for a given slope. The factor of safety is defined as the ratio of shear strength divided by the shear stress required for equilibrium of a slope. The structural and mechanical properties can be presented by a single design value (often an average) or by assigning a probability distribution function. 


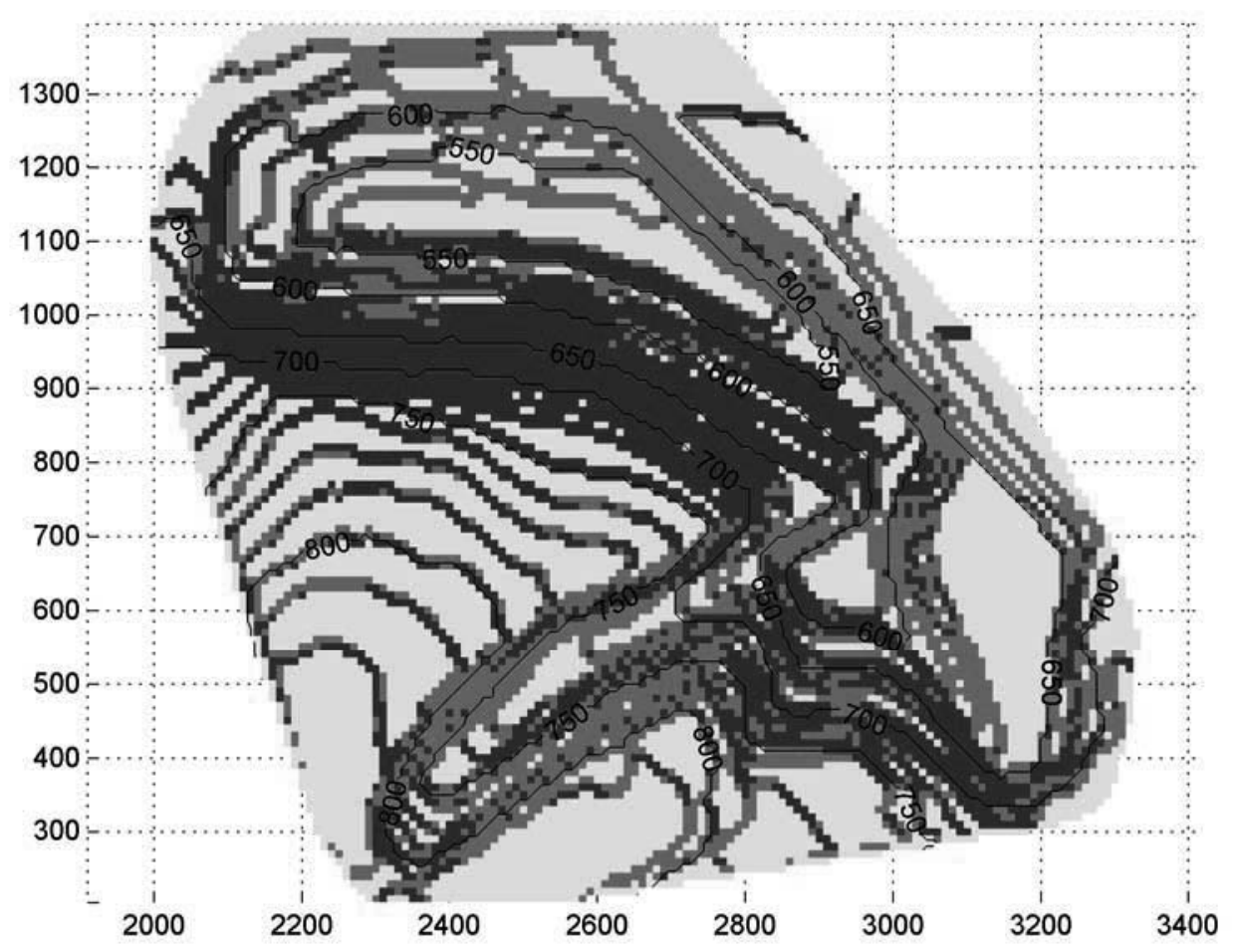

Figure 10 Map of kinematic feasible wedge instability (deterministic). Cells in dark gray are susceptible to failure

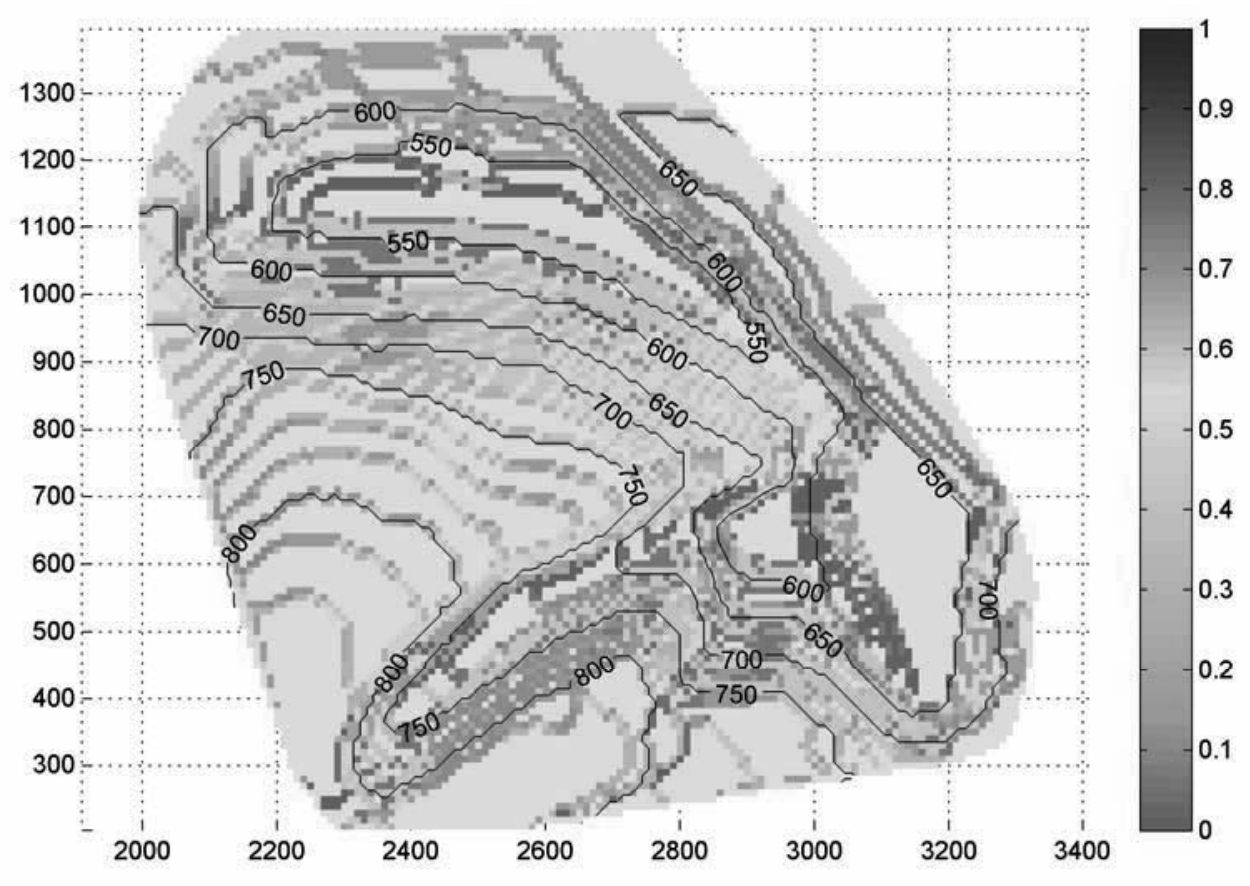

Figure 11 Map of kinematic feasible wedge instability (probabilistic). Displaying the maximum probability of failure for each cell

\subsubsection{Planar failure}

Figure 12 illustrates all slopes susceptible to planar failure that have a factory of safety less than 1 . These results were obtained using the mean values presented in Figure 2: dip, dip direction, friction angle and 
cohesion. If one compares the results with those presented in Figure 8, it is important to note that using the mechanical properties (friction and cohesion) of each regime results in only a few cells failing.

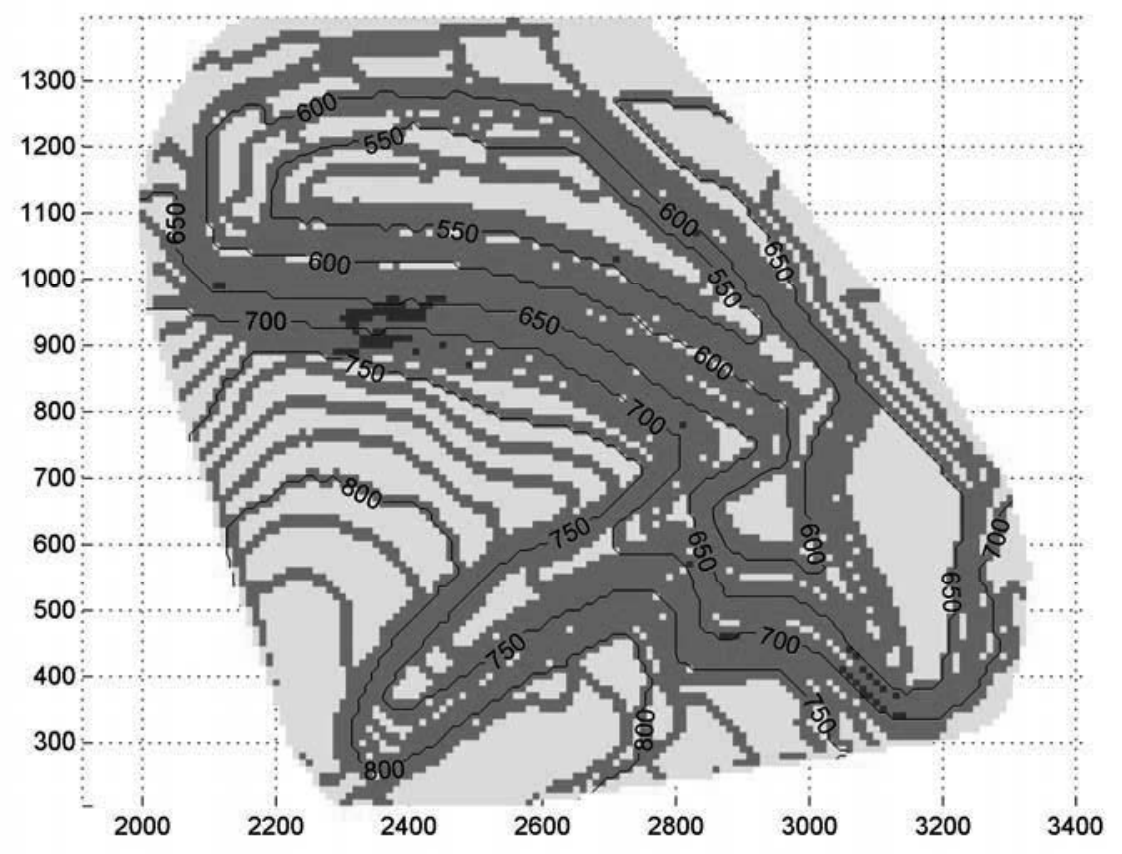

\section{Figure 12 Map of cells that predict planar failure (deterministic). Cells in dark grey have a factor of safety $<1$}

The concept of probability of failure $\left(\mathrm{P}_{\mathrm{f}}\right)$ is often used in limit equilibrium analyses to quantify potential instability.

$\mathrm{P}_{\mathrm{f}}=$ Number of Failed Wedges / Number of Samples

In this case study the number of wedge susceptible to failure are the number of wedges with a safety factor $<$ 1 , and the number of samples is 10,000. For example, for a given cell of domain (405) we have 4 sets. 10,000 fractures of every set were generated. The properties of each fracture of a given set may varied within the pdf function defining these properties. The kinematic feasibility analysis was performed on all those 10,000 realisations. The $\mathrm{P}_{\mathrm{f}}$ was then calculated at every cell. This approach is convenient is assessing the impact of variability of the input parameters on the results.

The results of the probabilistic analysis are illustrated in Figure 13. In this case it is noted that the probability of planar failure is relatively low under the currently available mechanical and structural conditions. Probability of failure alone is not in itself sufficient to fully capture the potential for slope instability. Priest and Brown (1983) have suggested the use of probability along with a factor of safety. In this worked example it was decided to use the minimum factor of safety calculated per cell, Figure 14. Reviewing the two figures it is recognised that although the probability of failure is small, there are areas where the resulting minimum factors of safety are low. These are areas that would justify monitoring and would potentially require more data collection for updated analyses.

\subsubsection{Limit equilibrium analysis for wedge failure}

The calculation of factor of safety for wedges susceptible to failure has been reviewed in all rock mechanics textbooks. In the GIS analysis this has been achieved by first determining the resulting tetrahedral wedge geometry based on block theory, Goodman and Shi (1985). The next step aims to determine all of the individual forces acting on a wedge, and then calculate the resulting active and passive force vectors for the wedge. Once the sliding direction is established the normal forces acting on each wedge plane are established and then it is possible to compute the resisting forces due to joint shear strength before determining the safety factor. 


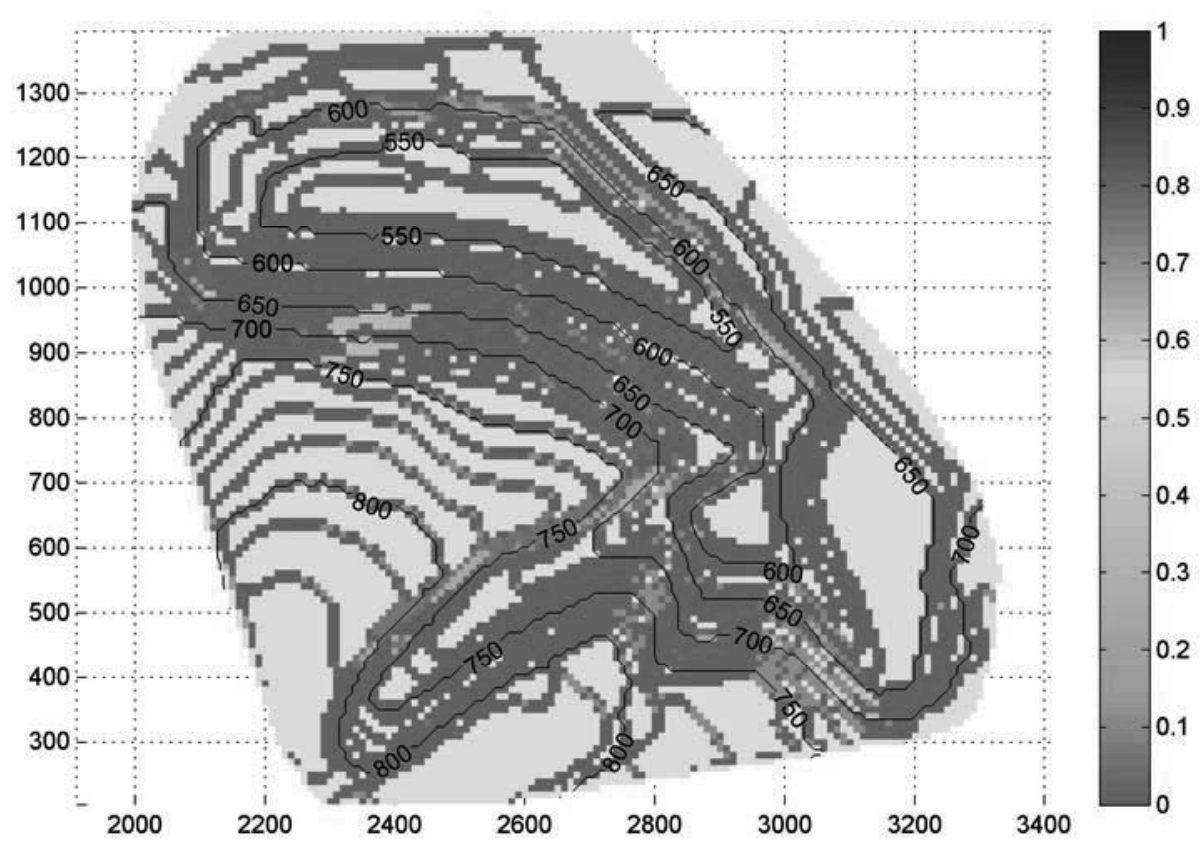

Figure 13 Map of cells that predict planar failure (probabilistic). Displaying the maximum probability of failure for each cell

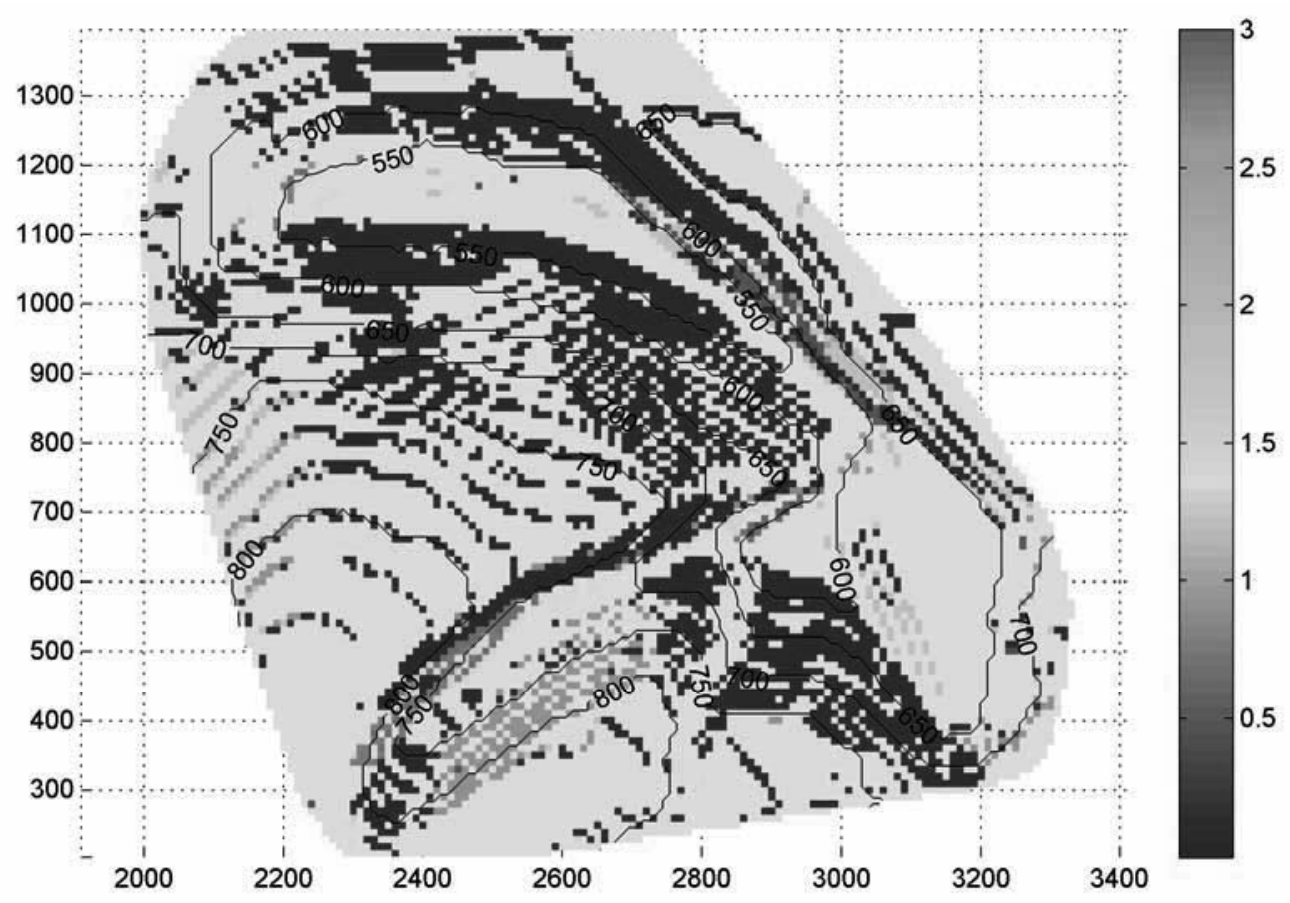

Figure 14 Map of cells that predict planar failure (probabilistic). Displaying the minimum factor of safety per cell

Figure 15 depicts the results of deterministic limit equilibrium analysis for wedge failure. In this case, based on the currently available structural and mechanical information, there are no areas in the pit that appear susceptible to wedge type failure. This analysis, however, was based on average input values only. 


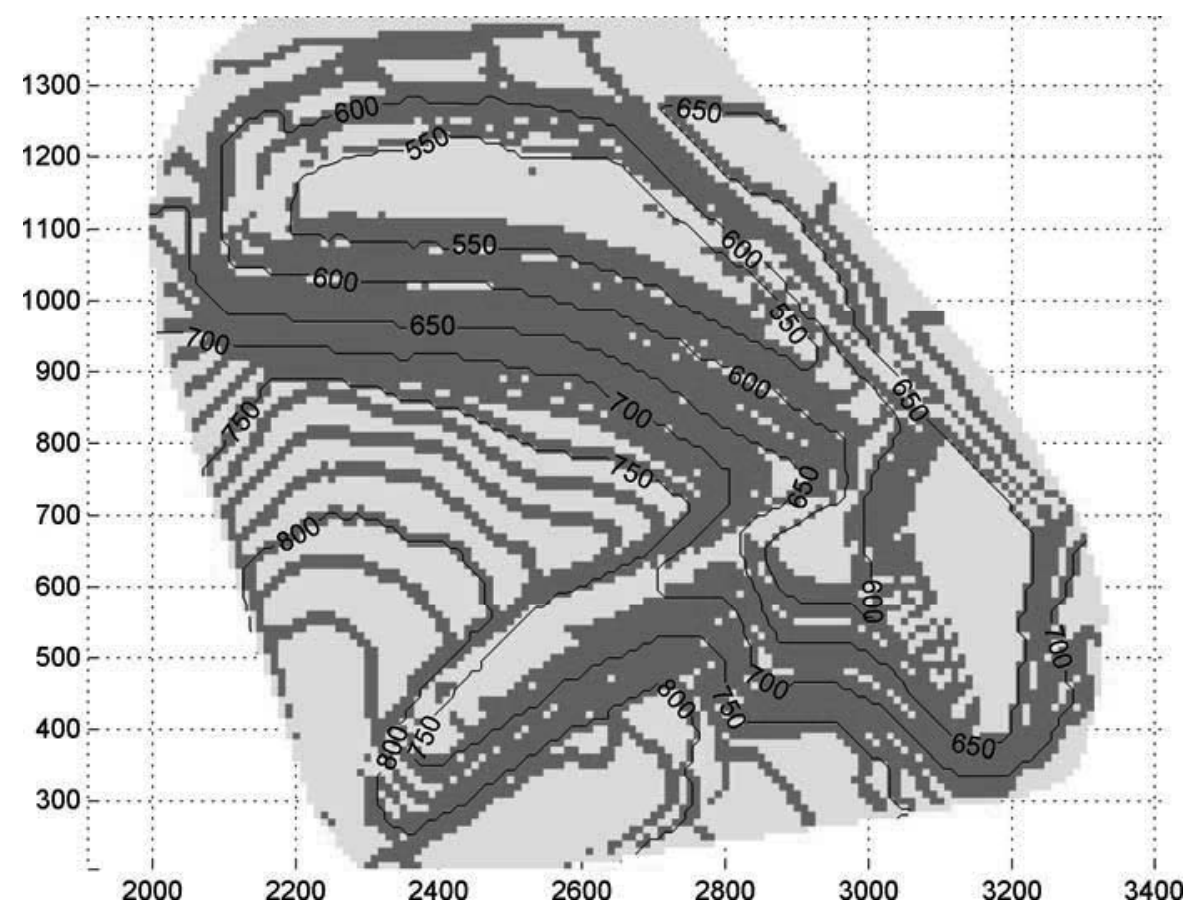

Figure 15 Map of cells that predict wedge failure (deterministic). Cells in dark grey have a factor of safety $<1$ (in this example no cells are unstable)

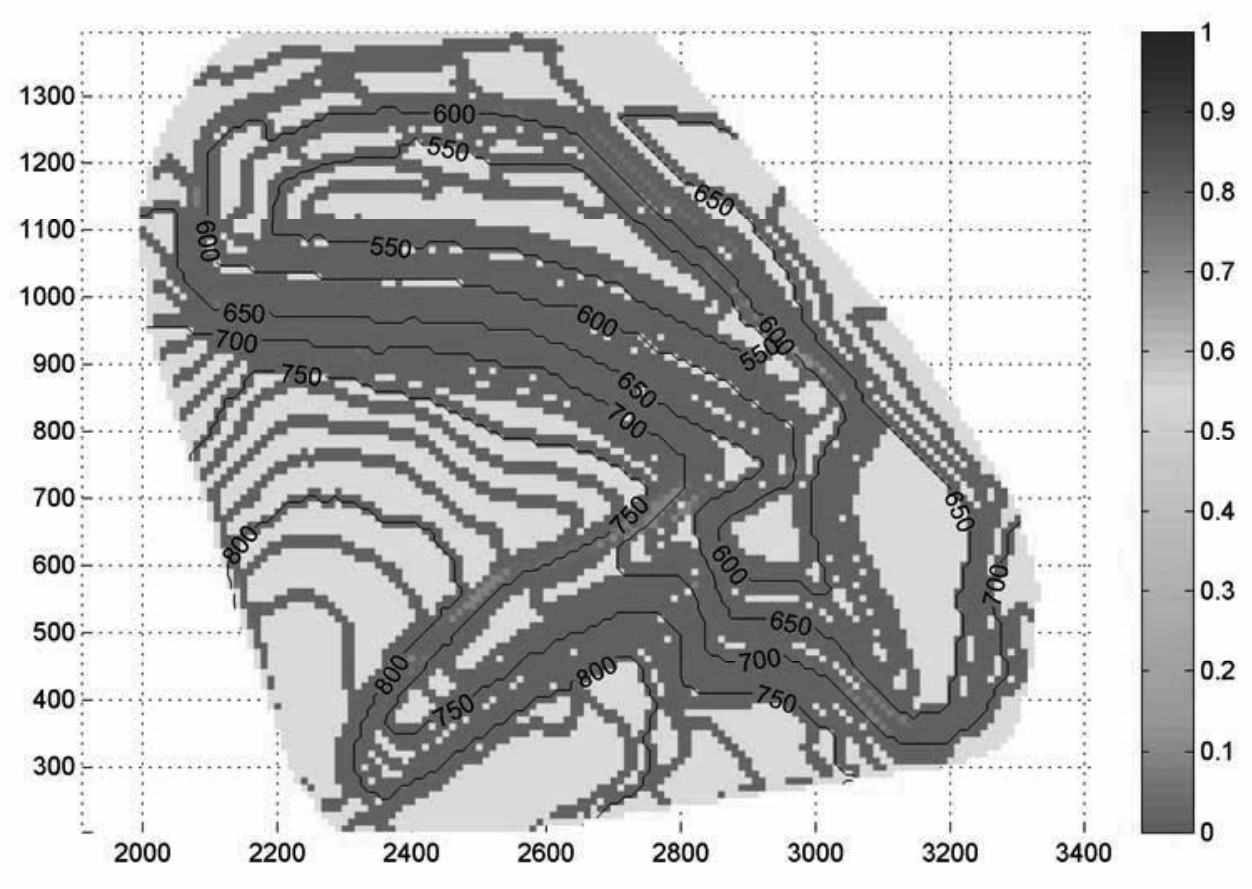

Figure 16 Map of LE probabilistic (wedge) for all cells. Displaying the maximum probability of failure for each cell

Figure 16 maps the probability of failure (wedge) for every cell. In this case the observed variance in all structural domains was accounted for through Monte-Carlo simulations. Again in this case there are very few cells that are of concern as the probability of failure is relatively low. 
The scope of the stability investigation was widened to calculate and plot the minimum factor of safety for wedge failure, Figure 17. As before, all calculations are computed for every cell. It is interesting to note that many cells have a minimal factor of safety less than two. If necessary this map can easily be recoded to represent the median of mean factor of safety.

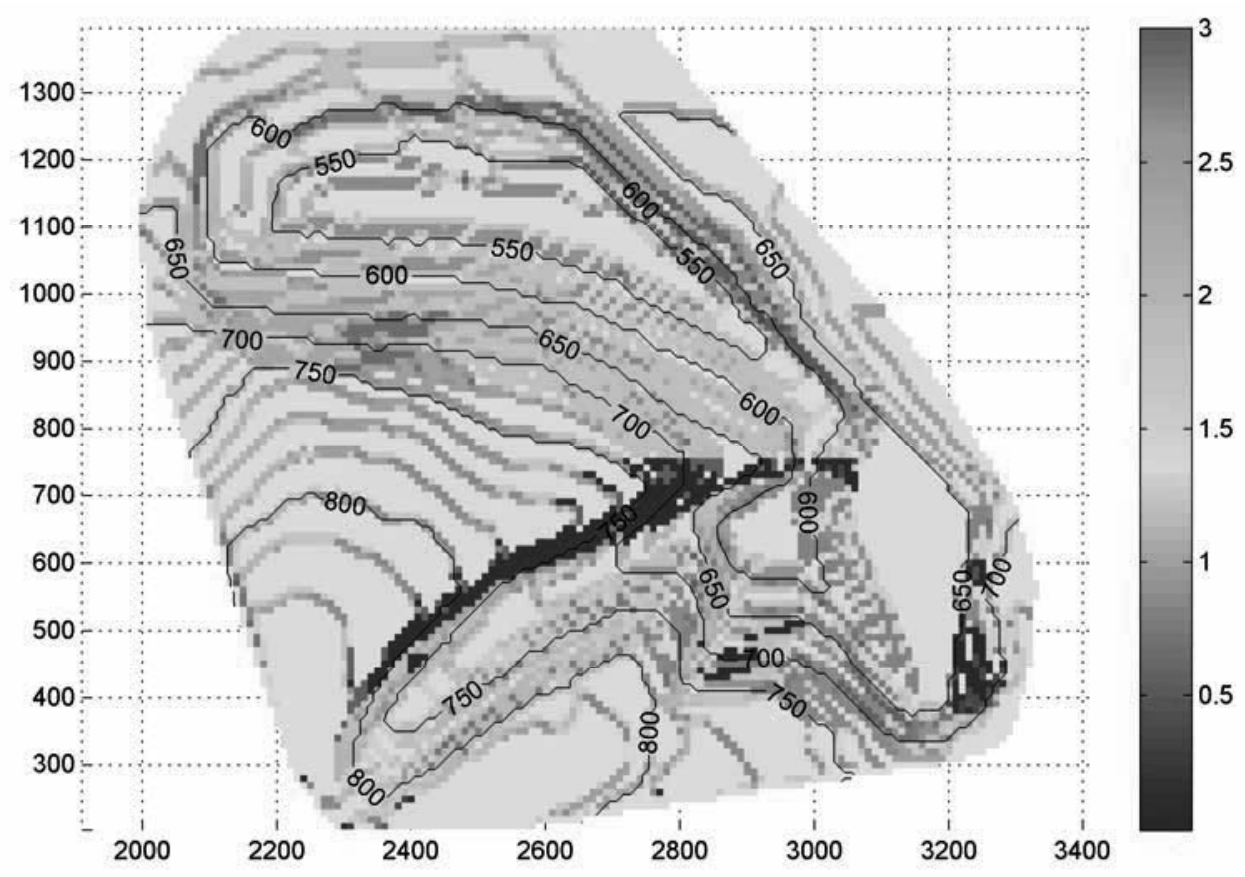

Figure 17 Map of LE probabilistic (wedge) for all cells. Displaying the minimum factor of safety

\section{Conclusions}

This paper has provided an integrated approach linking block modelling, pit optimization and slope stability analysis. A methodology has been implemented that allows for both deterministic evaluation of stability for an open pit based on spatially distributed geometric and geotechnical data. Furthermore, a series of developed algorithms have allowed the use of probabilistic techniques to develop susceptibility maps for any given pit configuration.

The stability issues in open pit planning have been addressed in this paper by dividing the pit into different structural domains. A series of kinematic analyses were conducted to establish the possibility of wedge and planar failure by sliding. This has resulted in a series of susceptibility maps for the pit. Limit equilibrium analyses were used to derive factors of safety. In determining the factor of safety, the full mechanical properties (angle of friction and cohesion) were used. The current coding can also facilitate sensitivity studies for the whole pit in a matter of minutes. In parallel with factor of safety analysis the probability of failure was determined for both planar and wedge failure. Duncan (2000) has reviewed the merits of applying traditional factor of safety analyses and reliability analyses to geotechnical problem and concluded:

"It is proposed that probability of failure should not be viewed as a replacement for factor of safety, but as a supplement. Computing both factor of safety and probability of failure is better than computing either one alone. Although neither factor of safety nor probability of failure can be computed with high precision, both have value and each enhances the value of the other."

The developed methodology allows for analysis along the whole pit, it is extremely time efficient to execute and can be easily updated as more information becomes available. The resulting 3-D visualisations are arguably a powerful tool for both at the engineering and management levels.

The results of this analysis are dependent on the quality of the database. Its inherent advantages are that as the quality of geomechanical data improves it is quite easy to update the analysis. Furthermore, different 
mine planning scenarios can be expediently explored. This is a major advantage given the iterative nature of open pit mine planning and design.

\section{Acknowledgements}

The authors would like to acknowledge the financial support of the Natural Science and Engineering Council of Canada.

\section{References}

Duncan, M.J. (2000) Factors of safety and reliability in geotechnical engineering. Journal of Geotechnical and Geoenvironmental Engineering, Vol. 126, No. 4, pp. 307-316.

Günther, A. (2003) SLOPEMAP: programs for automated mapping of geometrical and kinematical properties of hard rock hill slopes. Computers \& Geosciences, 29, pp. 865-875.

Goodman, R.E. and Shi, G-H. (1985) Block theory and its application to rock engineering. Prentice-Hall, pp. 338.

Hoek, E. and Bray, J.W. (1981) Rock slope engineering (Revised third edition) The Institution of Mining and Metallurgy, London (1981), $358 \mathrm{p}$.

Hudson, J.A. and Harrison, J.P. (1997) Engineering Rock Mechanics. Pergamon, 444 p.

Jaboyedoff, M., Couture, R. and Locat, P. (2004) Structural Analysis of Turtle Mountain (Alberta) Using Digital Elevation Model (DEM). $57^{\text {th }}$ Canadian geotechnical Conference, Quebec City.

Lerchs, H. and Grossman, I.F. (1965) Optimum design of open pit mines. CIM Bulletin, Vol. 58.

Little (2006) The benefit to open pit rock slope design of geotechnical databases. International Symposium on Stability of Rock Slopes in Open Pit Mining and Civil Engineering. The South African Institute of Mining and Metallurgy, pp. 97-116.

MathWorks (2006) MATLAB - The Language of Technical Computing (version 7.2) The MathWorks Inc., Natick.

Priest, S.D. (1993) Discontinuity Analysis for Rock Engineering. Chapman \& Hall, pp. 473.

Priest, S.D. and Brown, E.T. (1983) Probabilistic stability analysis of variable rock slopes. Trans. Inst. Min. Metall. (Sect A: Min. Industry), 92, January, pp. A1-A12.

Surpac Minex Group (2006) Surpac Vision - Resource Modelling and Mine Planning System (version 5.1) Surpac Minex Ltd., Vancouver.

Wyllie, D.C. and Mah, W. (2004) Rock Slope Engineering $4^{\text {th }}$ Edition. Spoon Press, 431 p. 